\title{
EKSTRAKSI DAN KARAKTERISASI SERAT ALAM DARI DAUN SANSE VIERIA LAURENTI DAN SANSEVIERIA ZEYLINIC
}

\author{
EXTRACTION AND CHARACTERIZATION OF NATURAL FIBERS \\ FROM SANSEVIERIA LAURENTI AND SANSEVIERIA ZEYLINIC \\ LEAVES
}

\author{
Ria Wanti ${ }^{1 *}$, Husni Dzulfikar ${ }^{1}$, dan Ryan Rudy ${ }^{1}$ \\ 1. Politeknik STTT, Bandung, 40272, Indonesia \\ ${ }^{*}$ E-mail : riawanti.kemenperin@gmail.com
}

\begin{abstract}
ABSTRAK
Penelitian ini bertujuan memahami potensi pemanfaatan Sansevieria laurenti \& Sansevieria zeylinic sebagai alternatif bahan baku benang tekstil. Makalah ini melaporkan proses ekstraksi \& karakterisasi properti serat dari daun tumbuhan Sansevieria laurenti \& Sansevieria zeylinic. Ekstraksi serat menggunakan metode water retting. Karakterisasi properti meliputi pengujian penampang melintang \& membujur, kekuatan \& mulur, kehalusan, panjang, kadar air, dan friksi. Data yang didapatkan digunakan untuk menganalisis kemampuan serat untuk dipintal. Serat Sansevieria laurenti memiliki penampang melintang berbentuk oval dengan beberapa berbentuk bulat, penampang membujur berbentuk silinder dengan dinding yang tebal, kekuatan 2,45 g/denier, mulur 7,08 \%, kehalusan 6,71 tex, panjang serat $32,1 \mathrm{~cm}$, moisture content $10,4 \%$, moisture regain $11,79 \%$, dan koefisien friksi 0,0295 . Sementara serat Sansevieria zeylinic memiliki penampang melintang berbentuk oval namun sebagian membentuk segitiga dengan sudut yang runcing, penampang membujur berbentuk silinder, kekuatan 2,19 g/denier, mulur 7,96 \%, kehalusan 4,54 tex, panjang serat $30,6 \mathrm{~cm}$, moisture content serat $10,8 \%$, moisture regain serat $12,37 \%$, dan koefisien friksi 0,0296 . Disimpulkan bahwa serat $\mathrm{S}$ ansevieria laurenti \& Sansevieria zeylinic memiliki potensi sebagai alternatif bahan baku benang tekstil. Serat dari daun tumbuhan S ansevieria laurenti \& Sansevieria zeylinic dapat digunakan sebagai alternatif bahan baku aplikasi tekstil.
\end{abstract}

Kata kunci : Sansevieria laurenti, Sansevieria zeylinic, serat daun, ekstraksi, karakterisasi 


\begin{abstract}
This study aimed to understand the potential use of Sansevieria laurenti $\&$ Sansevieria zeylinic as an alternative raw material for textile yarn. This paper reported the process of extraction \& characterization of the properties natural fibers from the leaves of Sansevieria laurenti \& Sansevieria zeylinic plant. The water retting method was used to extract the fiber. The fiber properties characterized were tested cross-section and longitudinal shape, strength $\&$ elongation, fineness, length, moisture regain, and coefficient of friction. The properties obtained were used to analyze the ability of fiber to be spun. Sansevieria laurenti fibers had an oval cross-section with some round shapes, longitudinal cylindrical sections with thick walls, strength 2,45 g/denier, elongation $7.08 \%$, fineness 6.71 tex, length $32.1 \mathrm{~cm}$, moisture regain $11.79 \%$, and coefficient of friction $0.0295 \mu$. Meanwhile, Sansevieria zeylinic fibers have an oval cross-section but some form a triangle with sharp angles, longitudinal cylindrical, strength $2.19 \mathrm{~g} /$ denier, elongation $7.96 \%$, fineness 4.54 tex, length $30.6 \mathrm{~cm}$, moisture regain $12.37 \%$, and coefficient of friction $0.0296 \mu$. It was concluded that Sansevieria laurenti $\&$ Sansevieria zeylinic fibers had potential as an alternative raw material for textile yarn. Fiber from the leaves of the Sansevieria laurenti $\&$ Sansevieria zeylinic plants could be used as an alternative material for textile application.
\end{abstract}

Key words: Sansevieria laurenti, Sansevieria zeylinic, extraction, characterization, leaf fiber

\title{
1. PENDAhUlUAN
}

Pemanfaatan berbagai jenis serat untuk tekstil, otomotif dan berbagai aplikasi struktural lainnya meningkat secara bertahap di abad ke-21 [6]. Serat sintetis banyak digunakan dalam berbagai aplikasi karena memiliki kekuatan yang baik namun memberikan dampak negatif pada lingkungan [25]. Beberapa tahun terakhir, kesadaran lingkungan meningkat [10]. Aspek ekologi menjadi hal yang diperhatikan akibat dari kemajuan teknologi industrialisasi yang berkembang cepat [9]. Produk tekstil dengan bahan ramah lingkungan

menjadi daya tarik bagi konsumen karena tidak mengandung bahan berbahaya dan dapat didaur ulang [9]. Oleh karena itu perlu adanya desain produk dengan memanfaatkan sumber daya alam [7]. Upaya untuk mencari sumber serat alternatif yang murah, berlimpah dan terbarukan sangatlah penting [17]. Penggunaan serat alami meningkat pesat didorong oleh masalah lingkungan dari serat sintetis [2]. Penggunaan bahan berbasis serat alami telah terbukti menjadi solusi efektif untuk mengurangi produksi berbasis serat sintetis ${ }^{[16]}$. 
Para peneliti telah menyelidiki serat alami sebagai pengganti serat sintetis yang dapat meningkatkan kinerja lingkungan [16]. Sebagian besar penelitian berkonsentrasi pada serat alami, seperti rami dan sisal, karena ketersediaannya yang luas [3]. Serat alam dapat diperoleh dari batang, daun, akar, buah dan biji tanaman. Vegetasi dieksploitasi karena kemampuannya menghasilkan serat langsung dari bentuk liar atau alami [15]. Prosesnya sederhana dan menghasilkan kualitas serat yang sangat baik [15]. Hal menarik dari serat alami yaitu biaya pemrosesan rendah, ringan, kekuatan sedang, modulus tinggi, biodegrabilitas, tidak berbahaya bagi kesehatan, serta kesesuaian untuk modifikasi kimia [11].

Serat daun dan kulit pohon merupakan sumber serat non-konvensional yang dapat dievaluasi untuk digunakan dalam industri tekstil [2]. Berbagai penelitian telah dilakukan terhadap serat alam konvensional seperti rami, kenaf, sisal, dan pisang. Akan tetapi, ada serat alam lainnya seperti spesies Sansevieria, Barkcloth, spesies Nettle, nanas yang belum dipelajari secara rinci [18]. Di dunia ada lebih dari 12 spesies Sansevieria [9]. Diantaranya yaitu tumbuhan Sansevieria laurenti dan Sansevieria zeylinic yang merupakan salah satu genus dari famili Agavaceae. Agavaceae merupakan salah satu famili dari kelas Lilliopsida. Tumbuhan ini tersebar baik di daerah tropis dan subtropis [11]. Tumbuhan ini sangat mudah untuk dibudidayakan karena dapat tumbuh di daerah yang memiliki sedikit air dan cahaya [13]. Tumbuhan Sansevieria memiliki kemampuan untuk menyerap gas polutan [26]. Tumbuhan ini mengandung serat alami yang berpontensi digunakan sebagai bahan baku industri tekstil [13]. Daun tanaman ini mengandung serat alami yang memiliki karakteristik yang sama dengan serat daun nanas. Ciri-ciri tersebut tidak mudah rapuh, mengkilat, dan panjang [26]. Berdasarkan keunggulan tersebut, tanaman ini sangat berpotensi dimanfaatkan untuk keperluan industri [26]

Makalah ini berfokus pada ekstraksi dan karakterisasi morfologi serta sifat fisika serat alam dari daun tumbuhan Sansevieria laurenti dan Sansevieria zeylinic. Tujuan utama dari penelitian ini adalah untuk memahami potensi pemanfaatan Sansevieria laurenti dan Sansevieria zeylinic sebagai alternatif bahan baku benang tekstil. 


\section{METODA PENELITIAN}

\subsection{Alat dan Bahan}

Peralatan yang digunakan untuk mengekstraksi serat yaitu wadah yang digunakan sebagai tempat ekstraksi serat, air bersih, dan sendok/benda tumpul untuk memisahkan serat dari zat lainnya. Sementara material yang digunakan yaitu daun tumbuhan Sansevieria laurenti dan Sansevieria zeylinic. Gambar daun tumbuhan Sansevieria dapat dilihat pada gambar 1.

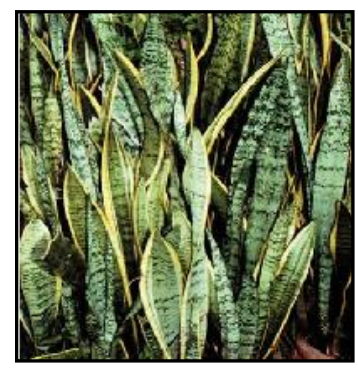

Tumbuhan Sansevieria laurenti dan serat Sansevieria zeylinic termasuk ke dalam salah satu genus dari family agavaceae. Tumbuhan ini dapat tumbuh subur di daerah yang kurang air \& sinar matahari [26]. Daun tumbuhan Sansevieria memiliki warna dan bentuk yang beragam, serta memiliki daun yang panjang ${ }^{[6]}$. Panjangnya $70-90 \mathrm{~cm}$ dengan lebar 5-6 cm. Daunnya mengandung serat alam yang memiliki karakteristik mirip dengan serat daun nanas ${ }^{[1]}$.

Gambar 1. daun tumbuhan

Sansevieria

\subsection{Metode}

Alur metode penelitian yang dilakukan dapat dilihat pada gambar 2 di bawah ini.

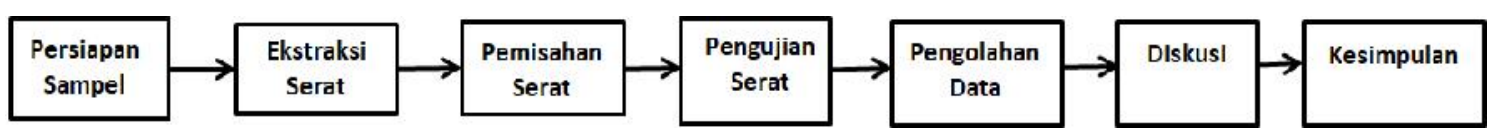

Gambar 2. alur metode penelitian

Serat dari daun tumbuhan Sansevieria laurenti dan Sansevieria zeylinic diekstraksi menggunakan metode water retting. Saat proses ekstraksi, 
mikroorganisme memisahkan serat dari biomassa lignosesulosa tanpa merusak serat selulosa ${ }^{[7]}$. Masing-masing daun tumbuhan Sansevieria laurenti dan Sansevieria zeylinic dengan berat kurang lebih 25 gram dimasukkan ke dalam wadah yang menyerupai bak, serat lalu direndam dengan air dan dibiarkan selama 3-4 minggu sampai daun membusuk yang ditandai dengan tekstur daun lembek, warna kecoklatan, dan timbul bau busuk. Kemudian dilakukan pengambilan serat dengan cara pengerukan (scrapping) menggunakan benda tumpul. Serat yang dihasilkan lalu dicuci untuk untuk membuang sisa lendir yang menempel. Serat lalu dikeringkan dengan cara dijemur selama 3-5 hari di tempat yang tidak terpapar sinar matahari secara langsung untuk menghindari pemutihan [1]. Serat lalu disisir dan ditimbang.

Pengujian serat Sansevieria laurenti dan Sansevieria zeylinic meliputi pengujian morfologi serat dengan melakukan pengujian penampang melintang dan membujur, serta pengujian sifat fisika serat yang meliputi pengujian kekuatan dan mulur, kehalusan, panjang berkas serat, moisture content \& moisture regain, serta koefisien friksi.
Pengujian penampang melintang dilakukan berdasarkan AATCC 201995 dan penampang membujur berdasarkan AATCC 20-1996. Pengujian menggunakan mikroskop dengan pembesaran 40 kali. Pengamatan penampang melintang dilakukan dengan cara memotong serat secara melintang setipis mungkin menggunakan alat bantu silet gabus, jarum, dan benang. Pengamatan penampang membujur dilakukan dengan memotong serat memanjang. Serat dikeringkan menggunakan oven dengan suhu $110^{\circ} \mathrm{C}$ selama 10 menit setelah itu diletakan pada preparat lalu ditutup dengan kaca penutup sehingga siap diamati di bawah mikroskop.

Pengujian kekuatan dan mulur serat dilakukan perbundel berdasarkan SNI 08-1112-1989 [20] menggunakan Mesin Uji Tarik dan Mulur Autodyn Tensolab. Sebundel serat yang sudah disisir dan diluruskan dibuat selebar $\pm 5 \mathrm{~mm}$ dengan berat $400-600 \mathrm{mg}$. Serat dipasang pada klem alat uji dengan jarak klem atas dan bawah $5 \mathrm{~cm}$ dalam kondisi rileks dan dibuat tetap lurus pada klem. Alat uji dinyalakan, saat serat putus dicatat kekuatan dan mulur serat. Bundel serat yang sebelumnya terpasang pada klem dipotong sepanjang sampel uji yaitu $5 \mathrm{~cm}$, lalu 
ditimbang. Pengujian dilakukan sebanyak 15 bundel. Lalu dihitung ratarata kekuatan dan mulur serat.

Pengujian kehalusan serat dilakukan berdasarkan SNI 08-1111-1989 [19]. Sekelompok serat disisir menggunakan sisir baja agar lurus, terurai dan sejajar lalu dipotong sepanjang $30 \mathrm{~mm}$, diambil 150 helai lalu ditimbang. Sampel dibuat sebanyak 10 ulangan. Kehalusan serat dihitung berdasarkan perbandingan berat dan panjang serat yang diuji.

Pengujian panjang serat dilakukan berdasarkan SNI 08-1113-1989 [21]. Seberkas serat yang sekurangkurangnya terdiri dari 100 helai diratakan ujung pangkalnya lalu diluruskan di atas bidang datar tanpa tegangan kemudian diukur panjang serat terpanjangnya. Sampel dibuat sebanyak 15 ulangan. Panjang serat adalah $80 \%$ dari rata-rata hasil pengukuran.

Pengujian moisture content (MC) dan moisture regain $(\mathrm{MR})$ dilakukan berdasarkan SNI 8100-2015 [22]. Satu gram serat dalam kondisi standar dikeringkan menggunakan oven dengan suhu $110^{\circ} \mathrm{C}$ selama satu jam, berat kering pertama serat ditimbang. Serat dikeringkan kembali dengan suhu $110^{\circ} \mathrm{C}$ selama 15 menit, berat kering kedua serat ditimbang. Berat kering dirata-ratakan, lalu moisture content (MC) dan moisture regain (MR) dihitung dengan membandingkan selisih antara berat standard dan berat kering dengan berat standar maupun berat keringnya. Pengujian koefisien friksi menggunakan metode point contact yaitu dengan menggesekkan serat pada serat sejenis untuk mengetahui nilai koefisien serat tersebut. Kedua ujung serat pertama dijepit secara horizontal pada alat uji koefisien friksi dalam kondisi lurus dan tegang, serat kedua disilangkan secara vertikal di tengah-tengah serat yang diletakkan horizontal (salah satu ujung serat dijepit, sementara ujung lainnya diberi beban). Saat serat sudah dalam kondisi bersilangan, serat yang arahnya horizontal dijalankan hingga tampak pergeserannya pada serat vertikal. Lalu diukur panjang pergeseran serat yang berada di garis horizontal dan vertikal. Sampel dibuat sebanyak 40 ulangan. Koefisien friksi lalu dihitung.

\section{HASIL DAN PEMBAHASAN}

\subsection{Ekstraksi Serat}

Serat Sansevieria laurenti dan Sansevieria zeylinic diekstraksi menggunakan metode water retting. Proses ekstraksi harus langsung 
dilakukan setelah daun dipotong agar gum pada daun tidak mengeras dan pulpa tidak menempel pada serat [7]. Proses retting diamati secara cermat pada interval waktu tertentu untuk mencegah retting berlebih yang akan membuat kerusakan pada serat [1,5]. Daun yang sedang diproses setidaknya harus dibalik sekali agar proses retting homogen [5]. Data hasil ekstraksi serat tercantum pada tabel $\mathbf{1}$, daun yang sudah melaui proses retting dapat dilihat pada gambar $\mathbf{3}$, dan serat yang dihasilkan dapat dilihat pada gambar 4. Diamati bahwa pembusukkan zat-zat perekat (gum substance) membutuhkan waktu 28 hari untuk serat Sansevieria laurenti dan 26 hari untuk serat Sansevieria zeylinica. Pengambilan serat dengan cara pengerukan (scrapping) menggunakan benda tumpul agar serat tidak rusak. Pencucian serat dilakukan untuk menghilangkan bahan pengikat serat yang masih menempel. Pengeringan dilakukan selama 3-5 hari, serat tidak boleh terpapar matahari secara langsung untuk menghindari pemutihan [26]. Serat kering disisir untuk menghilangkan jaringan lunak yang rusak [7, 1]. Serat Sansevieria yang dihasilkan berwarna putih kecoklatan akibat proses mikro organisme yang tumbuh pada serat tersebut [8]. Persentase serat yang dapat diambil dari daun Sansevieria laurenti sebesar $60 \%$, sementara dari daun Sansevieria zeylinic sebesar 55,39\%. Struktur mikro dan diameter serat yang dihasilkan dari ekstraksi water retting umumnya seragam dari ujung ke ujung, hal ini penting saat serat akan dipintal. 
Tabel 1. Data Hasil Ekstraksi Serat dari Daun Sansevieria Laurenti dan Sansevieria Zeylinica

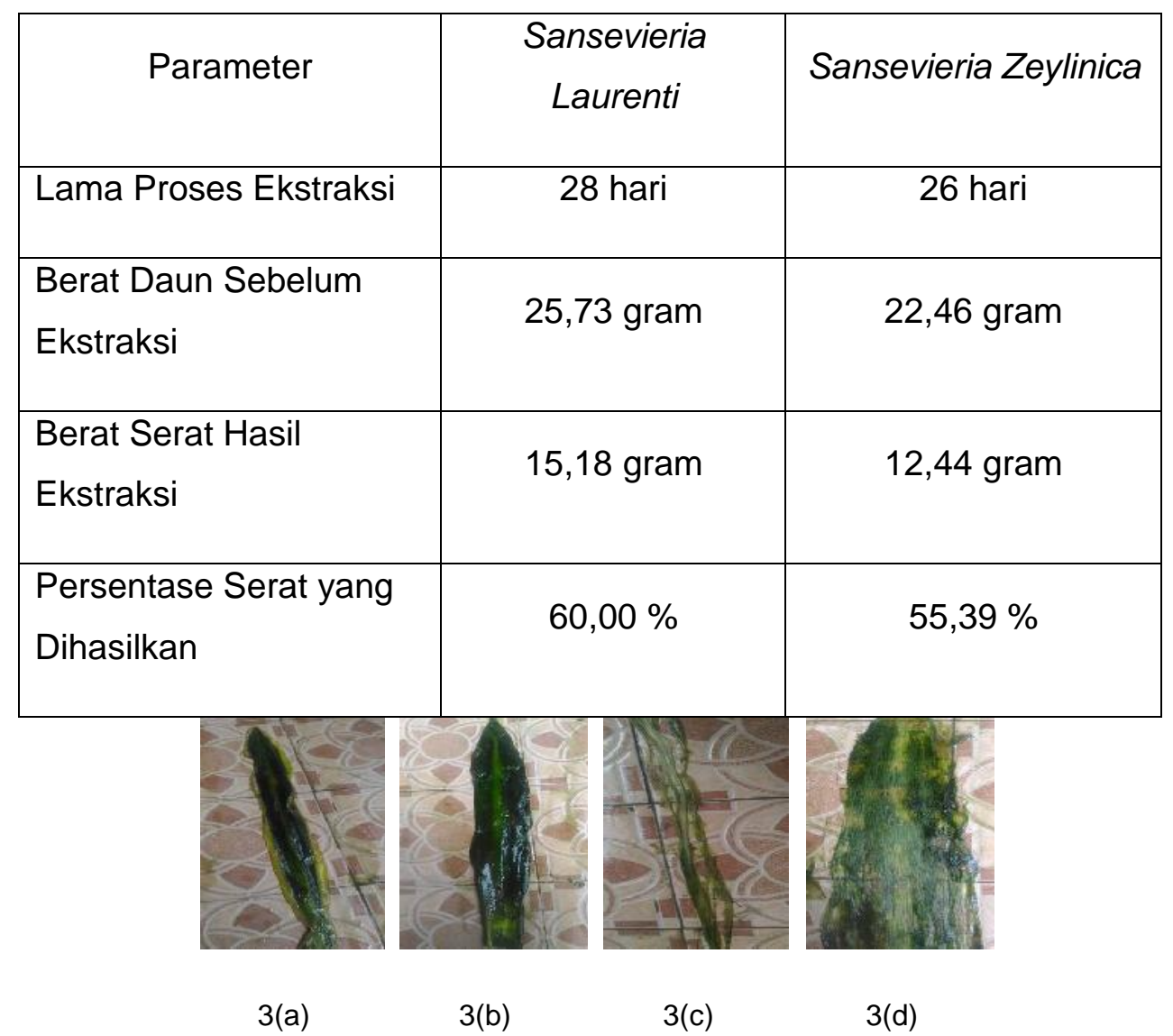

Gambar 3(a). daun sansevieria laurenti yang sudah melalui proses water retting; 3(b). daun sansevieria zeylinica yang sudah melalui proses water retting; 3(c). proses pemisahan serat sansevieria laurenti ; 3(d). proses pemisahan serat sansevieria zeylinica 


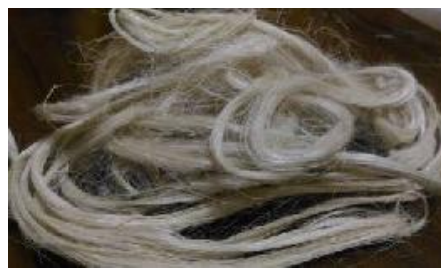

4(a)

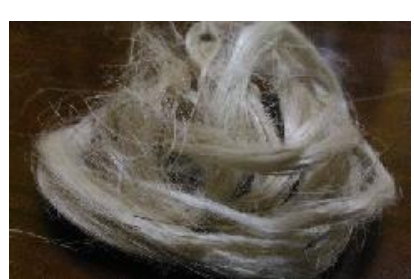

4(b)

Gambar 4(a). hasil ekstraksi serat sansevieria laurenti; 4(b). hasil ekstraksi serat sansevieria zeylinica

\subsection{Pengujian Serat}

Untaian serat Sansevieria laurenti dan Sansevieria zeylinic terdiri dari banyak serat individu. Gambar penampang melintang dan membujur serat dapat dilihat pada gambar $\mathbf{5}$. Terlihat di bawah mikroskop penampang melintang serat Sansevieria laurenti mayoritas berbentuk oval namun sebagian bentuknya hampir bulat sementara penampang melintang serat Sansevieria zeylinic mayoritas berbentuk oval menuju segitiga, sebagian membentuk sudut rucing. Penampang membujur serat Sansevieria laurenti dan Sansevieria zeylinica keduanya berbentuk silinder, namun dinding serat Sansevieria laurenti tampak lebih tebal. Pengujian dilakukan menggunakan mikroskop cahaya bukan dengan SEM maka perbesaran yang diperoleh terbatas. Pada diskusi eksperimen ini hanya membahas bentuk yang terlihat dari hasil pengujian dengan mikroskop cahaya, sementara terlihat bahwa serat berbentuk pejal. Akan tetapi untuk memastikan apakah serat ini juga berbentuk hollow seperti beberapa serat batang/daun lainnya diperlukan pengujian lebih lanjut dengan menggunakan SEM. 


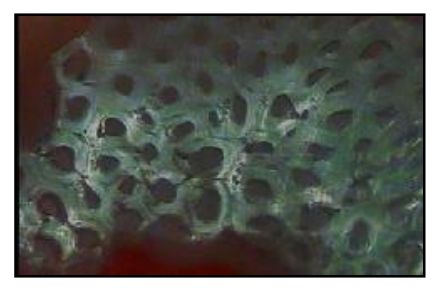

$5(a)$

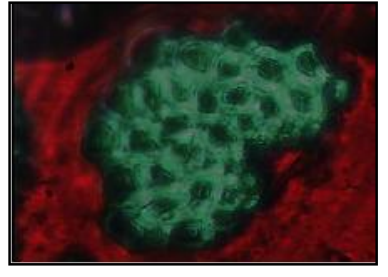

$5(b)$

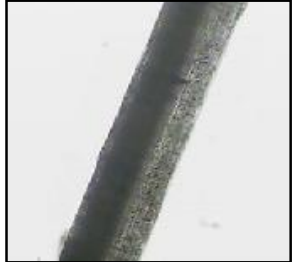

$5(c)$

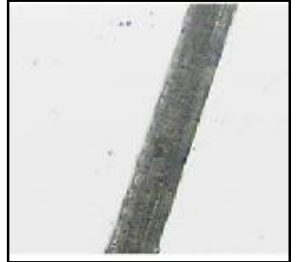

$5(d)$

Gambar 5(a). penampang melintang serat s. laurenti; 5(b). penampang melintang serat s. zeylinica; 5(c). penampang membujur serat s. laurenti; 5 (d). penampang membujur serat s. zeylinica

Data pengujian kekuatan, mulur, regain (MR), serta koefisien friksi serat kehalusan, panjang berkas serat, Sansevieria laurenti dan Sansevieria moisture content $(\mathrm{MC})$ \& moisture zeylinica tercantum pada tabel 2.

Tabel 2. Data Hasil Pengujian Serat Sansevieria Laurenti dan Serat Sansevieria Zeylinica

\begin{tabular}{|l|c|c|c|c|c|c|}
\hline \multirow{2}{*}{ Parameter } & \multicolumn{3}{|c|}{ Serat Sansevieria Laurenti } & \multicolumn{2}{c|}{ Serat Sansevieria Zeylinic } \\
\cline { 2 - 7 } & $\begin{array}{c}\text { Rata- } \\
\text { Rata }\end{array}$ & $\begin{array}{c}\text { Standar } \\
\text { Deviasi }\end{array}$ & $\begin{array}{c}\text { Coefisie } \\
\mathrm{n} \\
\text { Variasi }\end{array}$ & $\begin{array}{c}\text { Rata- } \\
\text { Rata }\end{array}$ & $\begin{array}{c}\text { Standar } \\
\text { Deviasi }\end{array}$ & $\begin{array}{c}\text { Coefisie } \\
\mathrm{n} \\
\text { Variasi }\end{array}$ \\
\hline Tenacity (g/tex) & 22,05 & 1,28 & 5,80 & 19,71 & 1,91 & 9,69 \\
\hline Tenacity (g/den) & 2,45 & 0,15 & 6,12 & 2,19 & 0,22 & 10,05 \\
\hline Mulur (\%) & 7,08 & 0,28 & 3,95 & 7,96 & 0,31 & 3,89 \\
\hline Kehalusan (Tex) & 6,71 & 3,93 & 58,57 & 4,54 & 2,62 & 57,71 \\
\hline $\begin{array}{l}\text { Panjang Serat } \\
\text { (cm) }\end{array}$ & 32,1 & 2,46 & 7,66 & 30,6 & 3,82 & 12,48 \\
\hline $\begin{array}{l}\text { Moisture Content } \\
\text { (\%) }\end{array}$ & 10,40 & 0,16 & 1,54 & 10,80 & 0,36 & 3,33 \\
\hline $\begin{array}{l}\text { Moisture Regain } \\
\text { (\%) }\end{array}$ & 11,79 & 0,20 & 1,70 & 12,37 & 0,45 & 3,64 \\
\hline Koefisien Friksi ( ) & 0,0295 & 0,0145 & 49,15 & 0,0296 & 0,0151 & 51,01 \\
\hline
\end{tabular}


Kekuatan adalah salah satu sifat penting yang harus dimiliki oleh serat karena akan mempengaruhi kualitas produk yang dihasilkan [6, 13]. Kekuatan adalah kemampuan serat untuk menahan beban regangan sebelum putus [2]. Faktor-faktor yang mempengaruhi kekuatan serat alami diantaranya, lokasi tumbuh, iklim, umur serat, pertumbuhan tanaman, kandungan selulosa, dan metode

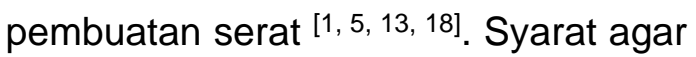
serat dapat dipintal menjadi benang harus memiliki kekuatan tarik yang lebih besar dari 1,2 g/denier [23]. Kekuatan serat Sansevieria laurenti sebesar 2,45 g/denier dan serat Sansevieria zeylinic 2,19 g/denier. Keduanya memenuhi persyaratan untuk dapat dipintal menjadi benang, nilainya juga lebih besar dari kekuatan serat wol (1,5 g/denier) yang saat ini sudah umum dimanfaatkan sebagai serat tekstil. Serat Sansevieria laurenti dan serat Sansevieria zeylinic cukup kuat karena memiliki kandungan selulosa yang tinggi. Kandungan selulosa pada serat berpengaruh linier terhadap kekuatan serat. Kadar selulosa serat Sansevieria mencapai $79 \%{ }^{[13]}$. Pada proses pemintalan, kekuatan sangat dibutuhkan karena serat akan mendapatkan banyak beban tarik, selain itu serat yang kuat juga akan menghasilkan benang yang kuat [13]. Mulur adalah salah satu sifat penting yang harus dimiliki oleh serat dan merupakan penentu apakah serat dapat dibuat menjadi produk tekstil [6]. Mulur merupakan kemampuan serat bertambah panjang saat diberi beban tarik sebelum putus. Mulur serat setidaknya harus 1-2\%, lebih tinggi lebih baik [6]. Mulur serat selulosa alami yaitu 2\% [5]. Mulur serat Sansevieria laurenti sebesar 7,08 \% dan serat Sansevieria zeylinic sebesar 7,96\%. Keduanya memiliki mulur yang cukup tinggi, lebih tinggi dari mulur serat kapuk $(3,8 \%)$ dan serat rami $(4,14 \%)$, serta mendekati mulur serat kapas (8\%) yang saat ini sudah umum digunakan sebagai serat tekstil. Serat Sansevieria laurenti dan serat Sansevieria zeylinic memiliki mulur yang tinggi karena memiliki kandungan lignin yang rendah yaitu $3 \%$, hal ini membuat serat dan produk yang dihasilkan tidak kaku [26]. Mulur serat berpengaruh linear terhadap mulur produk yang dihasilkan [6]. Semakin tinggi mulur, semakin baik performa dialami serat saat proses pemintalan [13]. Mulur yang tinggi membuat serat tidak mudah putus saat diproses. Serat dengan mulur yang tinggi jika dipintal akan menghasilkan 
benang yang halus. Produk yang dihasilkan diharapkan memiliki mulur yang cukup, sebagai contoh mulur harus cukup tinggi pada aplikasi pakaian di bagian lutut dan siku sehingga tidak kaku dan nyaman saat dipakai.

Kehalusan adalah salah satu karakteristik penting untuk mengevaluasi apakah serat dapat dipintal menjadi benang [9]. Kehalusan merupakan ukuran relative diameter yang dinyatakan dalam berat per satuan panjang [13]. Kehalusan berperan penting dalam menentukan menentukan kualitas benang yang dihasilkan [6]. Serat minimal harus memiliki rasio perbandingan panjang dan diameter $100: 1{ }^{[9]}$. Kehalusan pada benang menunjukkan jumlah serat yang ada di suatu penampang benang dengan ketebalan tertentu. Semakin banyak serat di sebuah penampang menunjukkan benang semakin kuat. Minimal dibutuhkan 30 serat dalam suatu penampang benang, tapi umumnya lebih dari 100. Syarat agar serat dapat dipintal menjadi benang harus memiliki kehalusan antara (2-8) tex ${ }^{[14]}$. Kehalusan serat Sansevieria laurenti sebesar 6,71 tex dan serat Sansevieria zeylinic sebesar 4,54 tex. Kehalusan kedua serat tersebut memenuhi persyaratan untuk dapat dipintal menjadi benang. Selain itu kehalusannya juga lebih unggul dibandingkan dengan serat sisal (1635) tex, serabut kelapa (25-50) tex, dan abaka (20-35) tex, serta hampir menyamai kehalusan serat jute $(1,25-5)$ tex, flax (2,5-6) tex, pisang (3-25) tex, dan serat nanas (2,5-6) tex. Namun kehalusan serat Sansevieria laurenti dan Sansevieria zeylinic masih jauh lebih kasar dari kehalusan serat kapas yaitu $(0,1-0,3)$ tex. Kehalusan serat akan berpengaruh pada kerataan benang yang dihasilkan karena jumlah serat yang halus pada ukuran penampang benang yang sama akan lebih banyak dibandingkan jumlah serat yang lebih kasar. Selain itu semakin halus serat (tanpa mempertimbangkan efek friksi) akan berbanding lurus dengan kekuatan serat per berkas karena jumlah serat yang berkontribusi terhadap kekuatan serat per berkas lebih banyak dari pada serat yang kasar [23].

Panjang serat adalah sifat terpenting yang menentukan kualitas dan kemampuan serat untuk dipintal [2]. Setiap serat memiliki struktur bentuk dan ukuran yang berbeda-beda bergantung pada sifat seratnya [13]. Rasio perbandingan panjang dan luas 
serat 4800 : 1 menunjukkan bahwa serat dapat dengan mudah dipintal [9]. Serat selulosa alami yang umum digunakan saat ini memiliki panjang lebih dari $2 \mathrm{~cm}$ [17]. Syarat agar serat dapat dipintal menjadi benang harus memiliki panjang lebih dari $3 \mathrm{~cm}{ }^{[14]}$. Panjang serat Sansevieria laurenti sebesar $32,1 \mathrm{~cm}$ dan serat Sansevieria zeylinic sebesar 30,6 cm. Keduanya memenuhi persyaratan panjang untuk dapat dipintal menjadi benang dan termasuk ke dalam kategori short to long staple fiber. Panjang serat yang dihasilkan sepanjang daun yang diproses, semakin panjang daun maka semakin panjang serat yang dihasilkan [2]. Panjang serat dipengaruhi oleh umur tumbuhan [17]. Pada proses pemintalan, semakin panjang serat yang digunakan akan menghasilkan benang yang semakin kuat karena serat panjang mempunyai permukaan yang besar yang menyebabkan gesekan antar serat menjadi lebih tinggi sehingga tidak mudah tergelincir [24]. Selain itu serat panjang menimbulkan lebih sedikit ujung serat yang menonjol di permukaan benang sehingga menghasilkan kain yang lebih halus dan menarik lebih sedikit partikel kotoran. Permukaan yang halus membantu memberikan kilau pada kain jadi.
Moisture Regain (MR) adalah indeks karakteristik kemampuan absorpsi uap air di udara yang merefleksikan karakteristik struktur serat [13]. Kelembaban tergantung pada komposisi serat, umur tumbuhan, kondisi iklim pertumbuhan tanaman [25]. Syarat agar serat dapat dipintal menjadi benang harus memiliki moisture content (MC) yang lebih rendah dari 12\% [14]. Serat Sansevieria laurenti memiliki moisture content (MC) sebesar 10,4\% dan moisture regain (MR) sebesar $11,79 \%$, sementara serat Sansevieria zeylinic memiliki moisture content (MC) sebesar 10,8\% dan moisture regain (MR) sebesar $12,37 \%$. Moisture regain (MR) serat Sansevieria laurenti dan serat Sansevieria zeylinic lebih unggul dibandingkan dengan serat kapuk (8\%) dan serat kapas $(8,5 \%)$ yang saat ini sudah umum digunakan sebagai serat tekstil [13]. Keduanya memenuhi syarat kandungan air untuk dapat dipintal menjadi benang dan termasuk ke dalam serat yang hidroskopis/menyerap air lebih banyak karena mempunyai banyak gugus hidroksil. MR yang baik menunjukkan bahwa serat siap menerima pewarna dan menjalani proses penyempurnaan dengan baik [2]. MR yang rendah membuat serat mudah rapuh/rusak 
saat diproses, kekuatannya menurun, mudah putus, serta berpengaruh terhadap panjang serat. Namun MR yang terlalu tinggi juga tidak disarankan karena membuat umur simpan serat lebih pendek, membuat serat terlalu basah dan mudah rusak.

Koefisien friksi serat Sansevieria laurenti sebesar 0,0295 $\mu$ dan serat Sansevieria zeylinic sebesar 0,0296 $\mu$. Nilai tersebut mirip dengan koefisien friksi serat rami $(0,0292 \mu)$ dan serat kenaf $(0,0295 \mu)$ yang saat ini sudah umum digunakan sebagai sserat tekstil. Berdasarkan Hukum Amonton, koefisien friksi berbanding lurus dengan gaya friksi $\left(\mathrm{F}_{\mathrm{g}}=\mu \times \mathrm{N}\right)$, friksi merupakan gaya yang timbul untuk menahan gesekan antar dua bidang kontak. Friksi pada serat diperlukan dalam proses pemintalan dan dapat mempengaruhi kekuatan benang yang dihasilkan [4]. Koefisien friksi dalam proses pemintalan dapat meminimalisir terjadinya efek selip yang akan menyebabkan terjadinya floating fiber (serat yang terapung) serta mempermudah pemberian twist pada benang ${ }^{[12]}$. Koefisien friksi yang sangat rendah pada serat menunjukkan bahwa serat tersebut memiliki permukaan yang licin yang menyebabkan seratserat mudah tergelincir dan memisahkan diri satu dari yang lain sehingga sukar untuk dipintal atau dapat dipintal namun menghasilkan benang yang kekuatannya rendah.

\section{KESIMPULAN}

Temuan penelitian ini memaparkan morfologi dan sifat serat Sansevieria laurenti dan serat Sansevieria zeylinic. Berdasarkan hasil karakterisasi, diperoleh bahwa serat Sansevieria laurenti dan serat Sansevieria zeylinic dapat diekstraksi dari daun tumbuhan dengan proses water retting sederhana yang tidak membutuhkan biaya yang tinggi. Berdasarkan hasil percobaan, ditemukan bahwa serat Sansevieria laurenti dan serat Sansevieria zeylinic memenuhi persyaratan untuk dijadikan sebagai alternatif bahan baku benang tekstil. Penampang melintang serat Sansevieria laurenti mayoritas berbentuk oval namun sebagian bentuknya hampir bulat sementara serat Sansevieria zeylinic mayoritas berbentuk oval menuju segitiga, sebagian membentuk sudut rucing. Penampang membujur serat Sansevieria laurenti dan Sansevieria zeylinica keduanya berbentuk silinder namun dinding serat Sansevieria laurenti tampak lebih tebal. Terlihat bahwa serat berbentuk pejal. Kekuatan tarik serat Sansevieria laurenti dan 
serat Sansevieria zeylinic lebih besar dari 1,2 g/denier dan kekuatannya juga lebih tinggi dari serat wol, memiliki mulur yang lebih tinggi dari serat kapuk dan rami, serta hampir menyamai serat kapas, memiliki kehalusan antara (2-8) tex dan kehalusannya juga lebih baik dari serat sisal \& abaka serta mendekati kehalusan serat nanas, memiliki panjang berkas serat yang lebih panjang dari $3 \mathrm{~cm}$ juga termasuk ke dalam kategori short to long staple, memiliki kadar air / moisture content
(MC) yang lebih rendah dari $12 \%$ dan termasuk ke dalam serat yang higroskopik / mampu menyerap lebih banyak uap air, memiliki koefisien friksi yang mirip dengan serat selulosa alami lain yang telah dipintal menjadi benang dan tidak memiliki permukaan yang licin. Oleh karena itu, dapat dinyatakan bahwa serat Sansevieria laurenti dan serat Sansevieria zeylinic berpotensi untuk digunakan sebagai alternatif bahan baku benang tekstil.

\section{DAFTAR PUSTAKA}

1. Aisyah, W. (2011). Kajian Morfologi, Anatomi dan Serat Daun Tanaman Sansvieria trifasciata yang Terdapat di Kota Malang. NATURAL B, Vol.1,No.2.

2. Azanaw, A. (2018). Extraction and characterization of fibers from Yucca Elephantine plant. http://doi.org/10.1007/s10570-018-2103-x.

3. Deshpande, A.P. (2000). Extraction of Bamboo Fibers and Theirs Use as Reinforcement in Polymer Composites. J ournal of Applied Polymer Science, Vol.76, 83-92.

4. Gupta, B.S. (2008). Friction in textile materials. Elsevier.

5. J ose, S. (2016). An Overview and Production, Properties and Value Addition of Pineaplle Leaf Fibers (PALF). Journal of Natural Fibers. http://dx.doi.org110.1080/15440478.2015.1029194.

6. Kant, R. (2013). Extraction of Fiber from Sansvieria Trifasciata Plant and its Properties. International Journal of Science and Research (IJ SR). www.ijsr.net.

7. Kilinc, A.C. (2017). Effect of Extraction Methods on the Properties of Altha OfficinaliL.Fibers.http://www.tandfonline.com/action/journallnformation? jou rnalCode=winf 0 . 
8. Kirby, R.H. (1963). Vegetable fibres, botany, cultivation and utilization. Vegetable fibres, botany, cultivation and utilization.

9. Knimozhi, M. (2011). Investigating the Physical Characteristics of Sansvieria trifasciata Fibre. International Journal of Scientific and Researh Publications, Volume 1, Issue 1. www.jjsrp.org

10. Manimaran, P. (2018). Synthesis and characterization of cellulosic fiber from red banana peduncle as reinforcement for potential applications. J ournal of Natural Fibers. http://doi.org/10.1080/15440478.2018.1434851.

11.N, Balaji. (2020). Experimental Investigation of Chemical and Tensile Properties of Sansvieria Cylindrica Fiber Composites. doi:10..4028/www.scientific.net/MSF.979.58.

12. Nair, A.U. (2013). Studies on friction in cotton textiles: Part II-A study on the relationship between physical properties and frictional characteristics of chemically treated cotton fabrics.

13. Napitupulu, L.O.Br. (2019). Kajian Proses dan Karakterisai Kain Tenun Serat Alamai Tanaman Lidah Mertua (Sansvieria trifasciata P.). J urnal Ilmiah Rekayasa Pertanian dan Biosistem, Vol.7, No.2. http://jrpb.unram.ac.id/.

14. Novarini. (2015). Potensi serat rami (boehmeria nivea s. gaud) sebagai bahan baku industri tekstil \& produk tekstil dan tekstil teknik. Balai Besar Tekstil, Bandung.

15. Rao, K.M.M. (2007). Extraction and tensile properties of natural fibers: Vakka, date and bamboo. Composite structures, 77, pp.288-295.

16. Reddy, K.O. (2014). Extraction and Characterization of Novel Lignocellulosic Fibers from Thespesia Lampas Plant. International Journal of Polymer Anal.Charact, 19:48-61. http://dx.doi.org/10.1080/1023666x.2014-854520.

17. Reddy, N. (2009). Extraction and Characterization of Natural Cellulose Fibers from Common Milkweed Stems. Wiley Interscience. www.interscience.wiley.com.

18. Rwawiire, S. (2015). Morphological, Thermal, and Mechanical Characterization of Sansvieria trifasciata Fibers. J ournal of Natural Fibers, 12:201-210. DOI:10.1080/15440478.2014.914006.

19. Standar Nasional Indonesia 08-1111-1989, Cara uji kehalusan serat batang. 
20.Standar Nasional Indonesia 08-1112-1989, Cara uji kekuatan tarik dan mulur serat batang perbendel.

21.Standar Nasional Indonesia 08-1113-1989, Cara uji panjang berkas serat batang.

22.Standar Nasional Indonesia 8100-2015 Cara uji kadar lembab (moisture content atau moisture regain) untuk tekstil.

23.Sukardan. (2017). Karakterisasi serat dari tumbuhan biduri (calotropis gigantea) dan identifikasi kemungkinan pemanfaatannya sebagai serat tekstil. J urnal IImiah Arena Tekstil.

24.Sulam, L.A. (2008). Teknik pembuatan benang dan pembuatan kain. Direktorat Pembinaan Sekolah Menengah Kejuruan.

25. Vinod, A. (2019). Extraction and Characterization of Natural Fiber from Stem of Cardiospermum Halicababum. Journal of Natural Fibers. http://doi.org/10.1080/15440478.2019.1669514.

26. Widyasanti, A. (2020). Physical and Mechanical Properties of Natural Fiber from Sansvieria trifasciata and Agava Sisalana. Earth and Environmental Science 462 (2020) 012032. doi:10.1088/1755-1315/462/1/012032. 